\title{
Regional Spotlights
}

\author{
Compiled by WBCRJ Staff \\ Sonoma State University \\ Sonoma County (CA)
}

\section{The German Wine Industry}

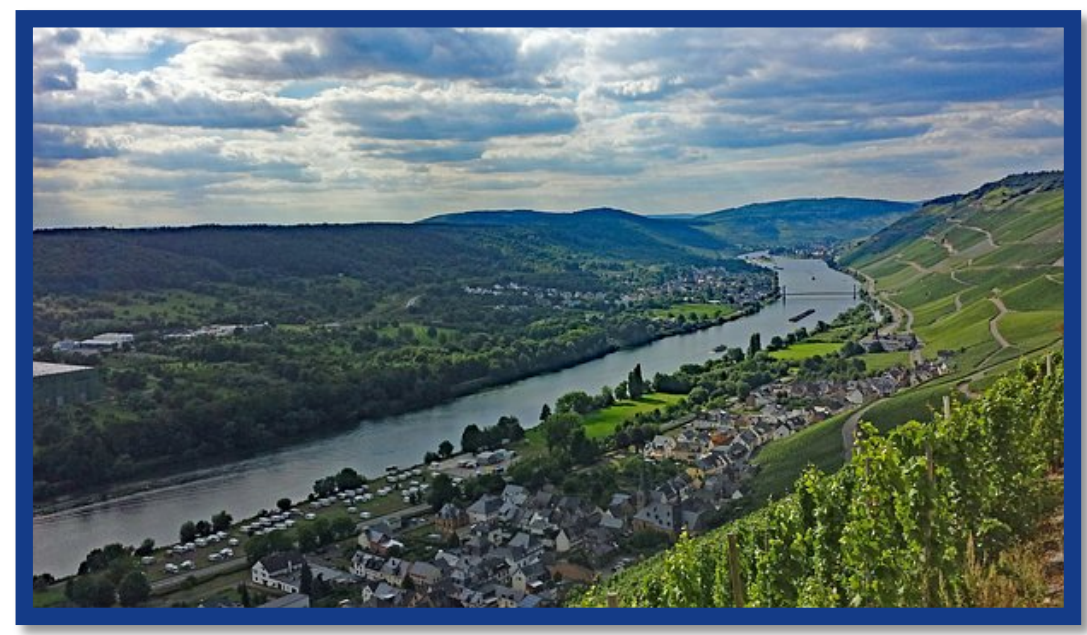

According to the German Wine Institute and Euromonitor, total harvest volume in 2015 reached 8.8 million hectoliters, which translated into a four percent decline compared with 2014. Germany is a net importer of wine. The total volume of net imports was 13.9 million hectoliters in 2015, primarily coming from Italy, Spain and France, which together accounted for $76 \%$ of total import volumes in that year. Imports of New World wine, such as wines from the United States (U.S.), South Africa, and Chile, increased in 2015, due to their attractive price-quality ratio. Exports of German wine fell to just over one million hectoliters in 2015. The most important export countries for German wine were the U.S., the Netherlands, and the United Kingdom (U.S.), both in volume and current value. However, demand for German wines from emerging markets in China and Japan remained stable in 2015. 
In Germany, wine tended to be consumed by slightly older consumer demographics. Quality is the most important factor impacting purchasing decisions when it comes to wine, and German consumers increasingly choose to sacrifice quantity for the benefit of quality, thereby driving up the average unit price. Growth in prices of high-value wine and continued premiumization of table wine are likely to occur, despite a projected two percent compound annual volume decline through 2021. Though older consumers' willingness to spend more on a bottle of quality wine is generally good news for wine producers, this also means that overall, younger consumers in Germany are generally less keen on drinking wine. The offpremises trade channel continues to outperform the on-trade channel in volume. German consumers enjoy drinking wine with or after dinner and have a strong preference for investing in a good bottle for home consumption, rather than paying high prices for possibly mediocre wine in on-premises establishments. German consumers in general are eco-conscious and possess a strong affinity for organic products, so there may be the potential for growth in organic wine, for which consumers are willing to pay more. 


\section{The Italian Wine Industry}

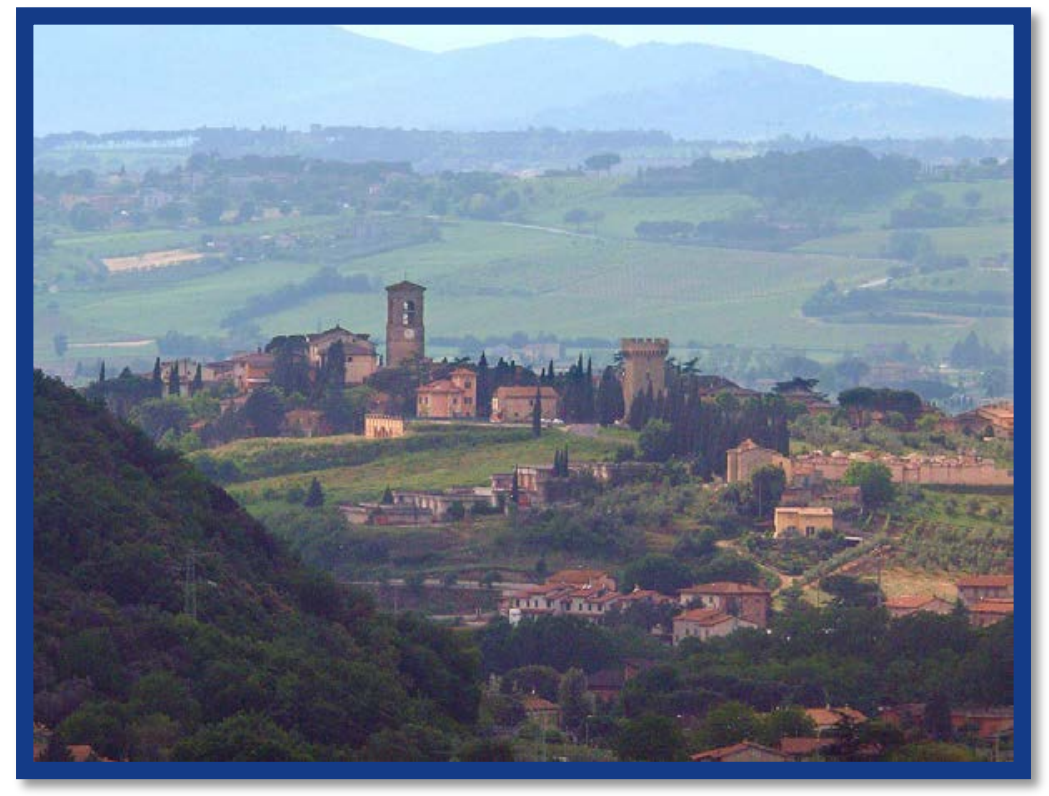

Wine sales in Italy registered a total volume growth of two percent in 2016, according to Euromonitor. Off-premises channels outperformed on-premises channels, a consequence of the prolonged Italian financial crisis and domestic consumers' greater preference for eating and drinking at home - to save money owing to shrinking disposable incomes. The best performing category within Italian wine in 2016 was sparkling wine — prosecco production increased strongly in 2016 due to its success domestically and internationally. Exports of Italian wine increased in 2016, primarily driven by the growth in popularity of prosecco. Outside the European Union (EU), the U.S. remained the leading export destination in value terms. Germany and the U.K. remained the main EU export destinations for Italian wines. Sparkling wines were forecasted by the industry to grow six percent by volume to 339 million liters, twice the anticipated compound annual growth for table wine (e.g. growing three percent by volume to 2.6 billion liters) by 2021.

There was a new trend towards natural wines. Natural wines promoted terroir and did not employ chemical products during their production. The growing popularity of natural wines resulted in consumer confusion regarding whether these wines were more sustainable environmentally and healthier than organic or "bio" wines, the latter continuing to remain a niche in the Italian wine industry. 


\section{The Spanish Wine Industry}

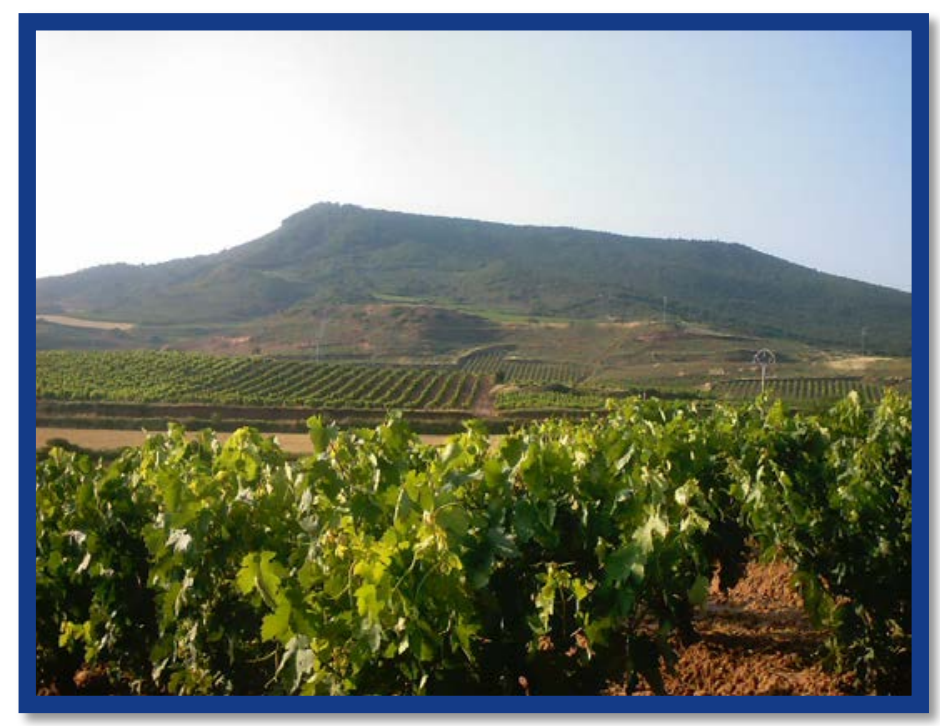

Euromonitor reported that the production of wine in Spain reached 2,922 million liters in 2016, a 6.5 percent decline in comparison with 2015. Spain was the world's third largest wine producer based on volume in 2016. With the exceptions of La Rioja, Castilla y León, Navarra and the Basque Country, all other regions of Spain witnessed drops in wine production volumes in 2016. Spain maintained its global position as the third leading wine exporter in value terms, behind France and Italy. Primary export destinations for Spanish wine were Germany, the U.K., France, Italy, and Portugal, although Spanish exporters had begun to focus on higher quality and value-added wine exports to countries such as China, the U.S., the Netherlands, and Ireland. According to the Spanish Observatory of the Wine Market, wine exports from Spain increased by 3.5 percent during the first half of 2016, to reach a total of $€ 2,669$ million by the end of June. The increases seen in value sales of Spanish wine particularly in sparkling wines such as cava - were thought to have compensated for the declines seen in volume sales.

Traditional consumers of wine in Spain tended to be middle-aged and older men. However, in recent years, products intended to appeal to women and younger consumers had led to the emergence of new lighter and fruity varieties of wine with lower alcoholic content, categorized as still white wine, still rosé wine, and other sparkling wine, that contributed to 
an expansion of the consumer base. During 2016, the increasing sophistication of Spanish consumers and rising demand for higher quality wine resulted in increasing sales of designation of origin varieties in the category, to the detriment of sales of table wine, which is the cheapest type of wine available in the country. Spain has more than 70 different designations of origin, with the most popular being Rioja, Valdepeñas, Rueda, Penedés, Rivera de Duero and Navarra, among others. Designation of origin was one of the main purchasing decision factors among local consumers of Spanish wine because it was associated with high quality. Although volume sales of wine witnessed positive growth in both the onpremises (+2 percent) and off-premises channels (+1 percent) in 2016, respectively, the onpremises performance of the category was supported by the rising confidence of Spanish consumers. Throughout 2016, the positive economic scenario in the country resulted in Spaniards spending more of their leisure time in bars and restaurants, especially in comparison with the several years of economic uncertainty which marked the economic recession, when very frugal consumption patterns and a significant drop in out-of-home spending led to falling sales generally in the consumer foodservice industry. Champagne recorded the highest total volume growth of any wine category in 2016, rising by seven percent. Increasing sales of champagne in the foodservice channel during the year was the result of rising spending on out-of-home leisure activities among Spanish consumers combined with increasing inbound tourist arrivals, particularly wine tourists. Cava, which was categorized under other sparkling wine, remained the most popular type of sparkling wine in Spain in 2016, with total volume sales of other sparkling wine standing at 35 million liters during the year compared with just three million liters of champagne.

As Spanish consumers shift towards higher quality products with higher prices and as more foreign wine tourists visit the country, wine sales in Spain by value were expected to grow two percent on a compound annual basis to $€ 1,074$ million by 2021. Champagne is forecasted to grow even faster - at an eight percent compound annual rate. Vermouth and still white wine sales are expected to increase in total volume at a seven percent compound annual rate. 


\section{The California Wine Industry: Monterey and Sonoma}

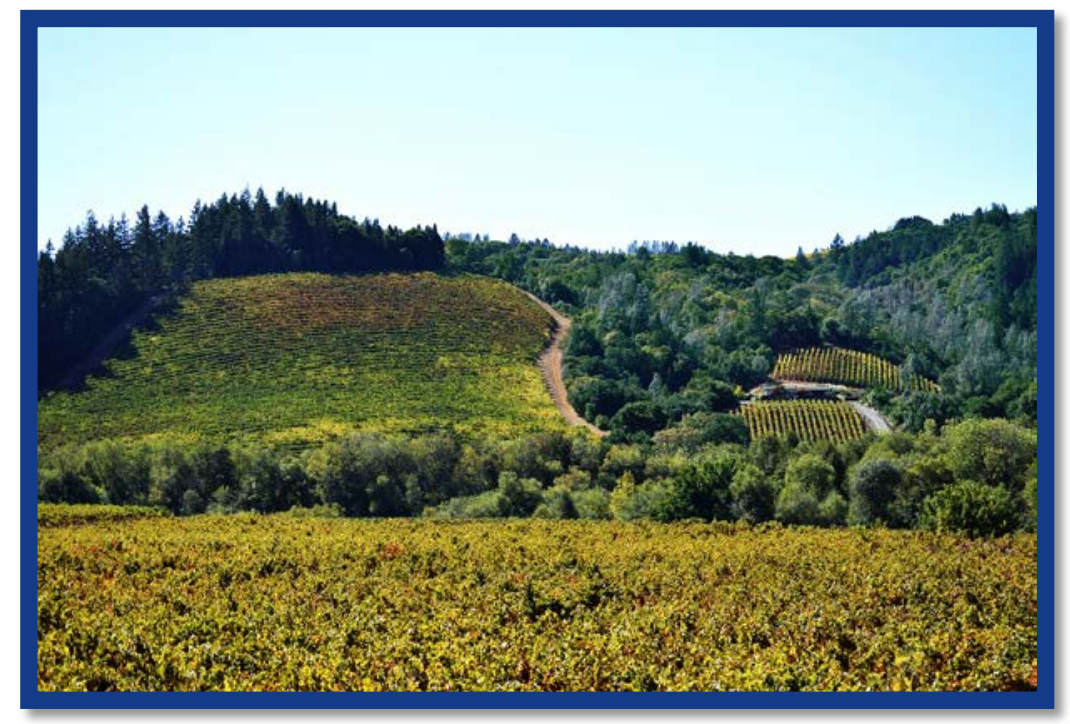

Euromonitor reported in 2017 that continued flux in the U.S. demographic makeup was assumed to be fundamental to the current state of the U.S. wine market. Aging baby boomers, the largest group of U.S. wine consumers and those most keen on the consumption of premium and luxury wines, were anticipated to decrease their rates of consumption. Meanwhile, millennials, determinedly unconventional, were expected to redefine the wine category as they matured, earned higher incomes, and developed greater familiarity with wine. Total volume sales of wine were expected to increase by an average annual amount of 267 million liters and at a two percent compound annual rate, reaching 3.4 billion liters in 2021 . Continued strength of the U.S. dollar and low oil prices could result in imported wines being relatively more affordable, while strong vineyard yields in California, the largest wine-producing area in the U.S. were expected to contribute to volume sales. The greatest threats to the growth of wine remained the ongoing craft revolution in the categories of beer and spirits and cannabis legalization. As rising input costs and lower pricing power continued to place pressure on profit margins in the U.S. wine industry, and as winery owners faced the inevitability of aging and the uncertainty over who would succeed them, consolidation within the U.S. wine market was anticipated to accelerate as smaller vineyards sought mergers and acquisitions as a means of increasing efficiencies and, in some instances, sidestepping the transition to the next generation. 
Monterey. According to Wines \& Vines, three wineries were big buyers of Central Coast grapes and bulk wine, and their needs were said to be growing: Francis Ford Coppola, Josh Cellars and Meiomi. Meiomi, which was sold in 2015 to Constellation Brands for \$315 million, produced about 700,000 cases of Pinot Noir and was expected to grow. Meiomi primarily sold a wine that was a blend of grapes from Sonoma, Monterey and Santa Barbara counties, and winemaker Melissa Stackhouse viewed Monterey as the source with the biggest growth potential. According to the California AG Network, Monterey vintners saw a more typical, temperate growing season in 2017 than they had witnessed in recent years that had been notable for declining production. Winter rains had produced excellent root flush and mild spring weather brought good bloom. Warm temperatures in late July helped the grapes transition to full ripeness. The harvest for sparkling wine grapes began the second week of August and in mid-September for still wine production. Record-breaking heat in early September caused Brix levels to jump, speeding up the harvest and causing logjams for some smaller wineries. The weather soon cooled and harvest slowed to a more normal rate. Yields were light to average, estimated at approximately 170,000 tons. The fruit appeared to be very good overall, with especially high quality in Pinot Noir, Chardonnay, Cabernet Sauvignon, and Merlot—all showing rich flavors.

Sonoma. The California AG Network reported that record-breaking winter rainfall kicked off the 2017 growing season in Sonoma County, filling the water table to capacity and replenishing soils. A mild spring brought bud break at the normal time, and vintners reported small berries with excellent color. A hot summer culminated in a Labor Day weekend heat wave that caused some vintners to move up their harvest dates by a week or so. The grapes endured the heat and once cooler weather arrived, fruit was able to mature at a gradual pace. Mid-September rain forced growers to open up canopies, and in some instances, use blowers to dry out certain varieties prior to harvesting. Early estimates predicted an average yield, but some vintners reported weight loss in the grapes after the heat wave. Because most of the fruit was picked prior to the October fire, vintners maintained a positive outlook on the 2017 wines, comparing the vintage to 2003, 2013, and 2014. The fruit had excellent color, pronounced flavors, and high quality across varieties. 


\section{References}

California Wine 2017 Harvest Report (Rep.). (2017). San Francisco, CA: California AG Network. Retrieved on February 11, 2018, from:

http://www.californiaagnet.com/2017/11/22/california-wine-2017-harvest-report/

Daniel, L. (2016, March 4). Demand High for Central Coast Grapes and Wine. Wines \& Vines Online. Retrieve on February 11, 2018, from:

https://www.winesandvines.com/news/article/166189/Demand-High-for-Central-CoastGrapes-and-Wine

Euromonitor International. (2017, June 1). Country Report: Germany. Retrieved from Euromonitor Passport database.

Euromonitor International. (2017, June 1). Country Report: Italy. Retrieved from Euromonitor Passport database.

Euromonitor International. (2017, June 1). Country Report: Spain. Retrieved from Euromonitor Passport database.

Euromonitor International. (2017, June 1). Country Report: USA. Retrieved from Euromonitor Passport database. 